\title{
圧縮性一様せん断乱流の直接計算手法*
}

\author{
藤原仁志*1, 松尾裕一*2, 荒川忠一*3
}

\section{Direct Simulation of Compressible Homogeneous Sheared Turbulence : A Numerical Procedure}

\author{
Hitoshi FUJIWARA, Yuichi MATSUO and Chuichi ARAKAWA
}

\begin{abstract}
A numerical procedure was derived to perform direct simulations of compressible homogeneous sheared turbulence. In this type of direct simulations, the pseudo-spectral method has often been used with the grid-remeshing procedure. However, this approach causes critical interpolation errors of the aliasing type. In this study, therefore, the grid was fixed and the finite-difference scheme was used in the shear-normal direction. As a result, precise data for compressible homogeneous sheared turbulence were obtained which are useful in analyzing the effect of compressibility on turbulence.
\end{abstract}

Key Words: Fluid Dynamics, Compressible Flow, Turbulent Flow, DNS, Turbulent Kinetic Energy, Dilatation Dissipation, Solenoidal Dissipation, Pressure-Dilatation Correlation

1. 緒言

平均速度が音速と同じオーダーになる高速流では, 乱 れ速度もまた音速と同じオーダーとなる叮能性がある。 このような流れの計算では, 乱流における圧縮性の影響, つまり密度の変動や乱れ速度の発散 $\left(\nabla \cdot \boldsymbol{u}^{\prime}\right)$ が 0 でない ことによる影響を原則として考虑する必要がある。し かし，現在では圧縮性流れの計算にも非压:縮性を仮定し た乱流モデルをそのまま用いることが多く、それなりの 成果をあげている。一方, 非常に圧縮性の影響の強い超 音速混合層の数值計算では, 非圧縮性を仪定した乱流モ デルを用いても実験值と一致する結果が得られない。 このため,圧縮性を考慮した乱流モデルを構築する試 みが活発に行なわれている(1，2，3，4)。また，それを組み 込んで計算を行なおうとする試みも多数なされている (5, 6, 7)。近年では各種の圧縮性乱流の直接計算 (DNS) も よく行なわれるが, その中で最も圧縮性の影響が顕著に 現れるのが一様せん断乱流の DNSで, その結果は乱流 モデルに圧縮性を組み込むための基本データとして頻 繁に利用される $(8,9)$ 。一様せん断乱流の D.NSでは, 移動 座標 (Lagrange座標) 上でスペクトル法を用いるという
手法(11)がよく用いられ，非圧縮性の計算(10)で一定の 成果をあげている。しかし、この種の計算では、計算途 中で定期的に行なわれる格子の remesh のもたらす誤差 が必ず問題になる。Remeshの際に発生する高波数部で の alias 誤差はかなり大きく、また alias 誤差を完全に除 去する手法がないこと、䛤差の程度が流れによって異な るためその正確な評価が難しいなどの問題はDNSとし ての計算の信頼性に関わる重要課題として残されてい る。これに対し,Ger(12)は差分法による固定座標(Euler 座標) 上での定式化を行ない, 全方向に 2 次の中心差分 を用いて計算することにより Remeshを回避している。 本研究では, スペクトル法の精度の良さを利用しつつ, 一部に高次精度差分を用いて Remesh を回避するとい う計算法を用いて圧縮性の一様せん断乱流の計算を行 なった。計算法について以下に解説する。

\section{2. 基礎方程式}

圧縮性を考慮した等方性ニュートン流体の基礎方程 式は次の通りである。ただし,動粘度・熱拡散係数は温 度によらず一定とし, 体積粘性 (bulk viscosity) は 0 とす

\footnotetext{
* 原稿受付 1996 年 3 月 14 日.

*1 学生員, 東京大学大学院 (\$113 東京都文京区本郷 7-3-1).

*2 航空宇宙技術研究所 (更 182 調布市深大寺東町 7-44-1).

*3 正員, 東京大学工学部.
} 
る。

$$
\begin{aligned}
\frac{\partial \rho}{\partial t}+\frac{\partial\left(\rho u_{j}\right)}{\partial x_{j}} & =0, \\
\frac{\partial\left(\rho u_{i}\right)}{\partial t}+\frac{\partial\left(\rho u_{j} u_{i}\right)}{\partial x_{j}} & =-\frac{\partial p}{\partial x_{i}}+\frac{\partial S_{i j}}{\partial x_{j}}, \\
\frac{\partial p}{\partial t}+u_{a} \frac{\partial p}{\partial x_{a}}+\gamma p \frac{\partial u_{a}}{\partial x_{a}} & =(\gamma-1)\left(\lambda \frac{\partial^{2} T}{\partial x_{a} \partial x_{a}}+S_{j k} \frac{\partial u_{j}}{\partial x_{k}}\right),(3) \\
S_{i j} & =\mu\left(\frac{\partial u_{i}}{\partial x_{j}}+\frac{\partial u_{j}}{\partial x_{i}}-\frac{2}{3} \frac{\partial u_{a}}{\partial x_{a}} \delta_{i j}\right),(4) \\
p & =\rho R T, \\
R & =C_{p}-C_{v}, \\
\gamma & =\frac{C_{p}}{C_{v}} .
\end{aligned}
$$

これを以下のように無次元化する。

速度 $a_{r} ：$ 初期条件の平均音速

長さ $l_{r}:$ 計算領域の一辺の長さ $/ 2 \pi$

密度 $\rho_{r}$ ：初期条件の平均密度

粘度 $\mu_{r}$ : 定数

压力 $p_{r}: \rho_{r} a_{r}^{2}$

温度 $T_{r}: a_{r}^{2} / \gamma R$

熟伝導率 $\lambda_{r}$ : 定数

比熱比 $\gamma$ : 定数 $(=1.4)$

無次元化された基礎方程式は

$$
\begin{aligned}
& \frac{\partial \rho}{\partial t}+\frac{\partial\left(\rho u_{j}\right)}{\partial r_{j}}=0, \\
& \frac{\partial\left(\rho u_{i}\right)}{\partial t}+\frac{\partial\left(\rho u_{j} u_{i}\right)}{\partial x_{j}}=-\frac{\partial p}{\partial x_{i}}+\frac{\partial S_{i j}}{\partial r_{j}} \text {. } \\
& \left.\frac{\partial p}{\partial t}+u_{a} \frac{\partial p}{\partial x_{a}}+\gamma p \frac{\partial u_{a}}{\partial x_{a}}=\frac{1}{\operatorname{RePr}} \frac{\partial^{2} T}{\partial x_{a} \partial x_{a}}+(;-1) S_{j k} \frac{\partial u_{k}}{\partial x_{j}} 10\right) \\
& S_{i j}=\frac{1}{R e}\left(\frac{\partial u_{i}}{\partial x_{j}}+\frac{\partial u_{j}}{\partial x_{i}}-\frac{2}{3} \frac{\partial u_{a}}{\partial x_{a}} \delta_{i j}\right)(11) \\
& p=\frac{1}{\gamma} \rho T \text {, } \\
& \text { Re }=\frac{\rho_{r} a_{r} l_{r}}{\mu_{r}}, \\
& \operatorname{Pr}=\frac{C_{p} \mu_{r}}{\lambda_{r}} \text {. }
\end{aligned}
$$

となる。

\section{3. 一様せん断乱流}

一様せん断乱流については,従来から移動座標上でス ペクトル法を用いるという手法が有力であるが, Remesh の際に発生する alias 誤差の問題があることは説明し た。これに対し、一部に差分法による定式化を導入する ことによりRemeshを回避することが出来る(12)。以下 に,移動座標上でスペクトル法を用いた場合の定式化と Remeshによる alias 誤差の発生について説明し，その後、 本研究で用いた手法について説明する。座標系につい ては図1のように設定する。せん断強さを $S \equiv d U / d x_{2}$ とすると平均速度べクトルは

$$
\overline{\boldsymbol{u}}=\left(S x_{2}, 0,0\right),
$$

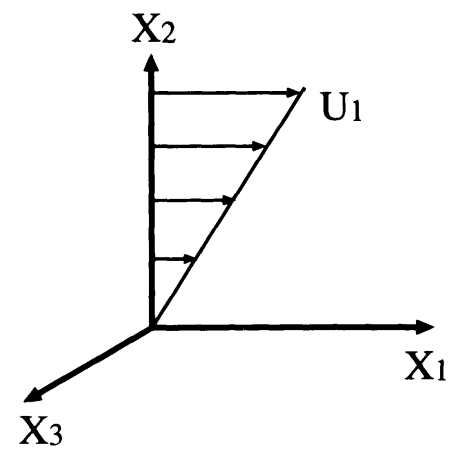

Fig. 1 Coordinate system

であるから,速度べクトルをレイノルズ分解すると

$$
\left\{\begin{array}{l}
u_{1}=S x_{2}+u_{1}^{\prime}, \\
u_{2}=u_{2}^{\prime}, \\
u_{3}=u_{3}^{\prime},
\end{array}\right.
$$

となる。ここで無次元化された基礎方程式系を $\left(u_{1}^{\prime}, u_{2}^{\prime}, u_{3}^{\prime}, \rho, p\right)$ を変数として書き直すと

$$
\begin{aligned}
& \rho_{. t}+S x_{2} \rho_{.1}+\left(\rho u_{j}^{\prime}\right)_{. j}=0 . \\
& \left(\rho u_{i}^{\prime}\right)_{. t}+S x_{2}\left(\rho u_{i}^{\prime}\right)_{, 1}+\left(\rho u_{j}^{\prime} u_{i}^{\prime}\right)_{. j}=-\rho S u_{2}^{\prime} \delta_{i 1}-p_{, i} \\
& +\frac{1}{R e}\left\{u_{i . a n}^{\prime}+\frac{1}{3}\left(u_{a, a}^{\prime}\right)_{. i}\right\} \text {, } \\
& p_{, t}+S r_{2} p_{, 1}+u_{a}^{\prime} p_{, a}=-\gamma_{p} u_{a, a}^{\prime}+\frac{\gamma(p / \rho)_{, a n}}{\operatorname{Re} P_{r}}+\frac{(\gamma-1) \Phi}{\operatorname{Re}}, \\
& \Phi \equiv u_{a, b}^{\prime}\left(u_{a, b}^{\prime}+u_{b, a}^{\prime}\right)+2 S\left(u_{1.2}^{\prime}+u_{2.1}^{\prime}\right)+S^{2}-\frac{2}{3} u_{a, a}^{\prime} u_{b, b}^{\prime} .
\end{aligned}
$$

3・1 スペクトル法による計算方法＼cjkstart前節の一 様せん断流の基礎式において $x_{2}$ を含む項はスペクトル 法では扱いができないため、次のような座標変換を行な う。

$$
\left\{\begin{array}{l}
t^{*}=t, \\
x_{1}^{*}=x_{1}-S x_{2} t, \\
r_{2}^{*}=x_{2}, \\
x_{3}^{*}=x_{3} .
\end{array}\right.
$$

この座標系は平均流と共に変化する Lagrangn 的な座標 と言える(図2参照)。この変換を用いると,基礎方程式
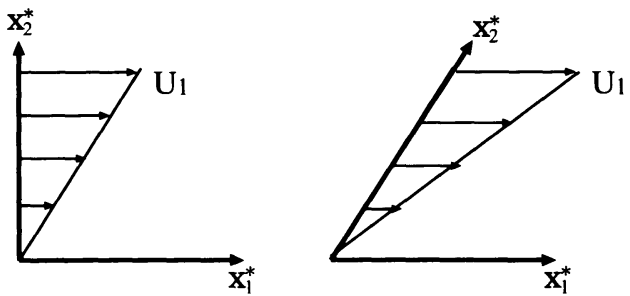

Fig. 2 Lagrange coordinate system 
をスペクトル法が適用可能な形にかける。ところで, 図 2に示した通りこの座標系は平均流と共に変化するた め, 次第に格子が歪んでしまい直交性が非常に悪くな る。さらに,そのまま放置し続けると最後には計算不能 になる。これを回避するため, 45 度格子が歪んだ時点で 座標変換を行ない格子を元に戻すという操作を行なう (図3参照)。

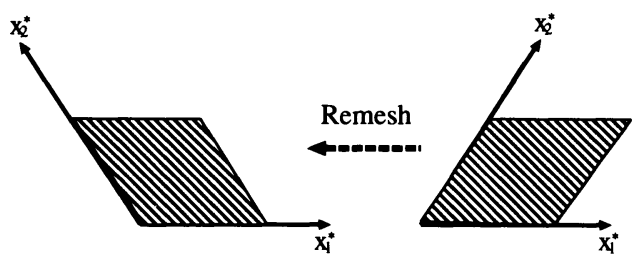

Fig. 3 Remeshing procedure

この操作は式の上では次のようになる。座標系 $\left(x_{1}, x_{2}, x_{3}\right)$ を $\left(x_{1}^{\prime}, x_{2}^{\prime}, x_{3}^{\prime}\right)$ に remeshするとすれば

$$
\left\{\begin{array}{l}
x_{1}^{\prime}=x_{1}+x_{2}, \\
x_{2}^{\prime}=x_{2}, \\
x_{3}^{\prime}=x_{3},
\end{array}\right.
$$

という関係がある。ここで,Remeshの操作が一般の物 理値 $\phi\left(x_{1}, x_{2}, x_{3}\right)$ に与える影䉡について考える。

$$
\phi=\sum_{\boldsymbol{k}} \hat{\phi}\left(k_{1}, k_{2}, x_{3}\right) \exp \left[i\left(k_{1} x_{1}+k_{2}, x_{2}\right)\right],
$$

とおいて座標変換をすると,

$$
\phi=\sum_{\boldsymbol{k}} \hat{\phi}\left(k_{1}, k_{2}, x_{3}\right) \exp \left[i\left(k_{1} x_{1}^{\prime}+\left(k_{2}-k_{1}\right) x_{2}^{\prime}\right)\right],
$$

となる。ここで,

$$
\left\{\begin{array}{l}
k_{1}^{\prime}=k_{1} \\
k_{2}^{\prime}=k_{2}-k_{1}
\end{array}\right.
$$

とおけば,

$$
\phi=\sum_{\boldsymbol{k}^{\prime}} \widehat{\phi}\left(k_{1}^{\prime}, k_{1}^{\prime}+k_{2}^{\prime}, x_{3}\right) \exp \left[i\left(k_{1}^{\prime} x_{1}^{\prime}+k_{2}^{\prime} x_{2}^{\prime}\right)\right] .
$$

Remesh した後のスペクトルを $\widehat{\phi}_{R}$ とおけば

$$
\phi=\sum_{\boldsymbol{k}^{\prime}} \widehat{\phi}_{R}\left(k_{1}^{\prime}, k_{1}^{\prime}, x_{3}\right) \exp \left[i\left(k_{1}^{\prime} x_{1}^{\prime}+k_{2}^{\prime} x_{2}^{\prime}\right)\right],
$$

となるはずなので,Remeshする前のスペクトルとRemesh した後のスペクトルには

$$
\widehat{\phi}_{R}\left(k_{1}^{\prime}, k_{2}^{\prime}, x_{3}\right)=\hat{\phi}\left(k_{1}^{\prime}, k_{1}^{\prime}+k_{2}^{\prime}, x_{3}\right),
$$

の関係がある。ところで波数 $k_{1}^{\prime} や k_{2}^{\prime}$ には当然範囲が あるので, $\widehat{\phi}$ から $\widehat{\phi}_{R}$ を求めようとすると.高波数のほう で $\hat{\phi}_{R}$ に対応する $\hat{\phi}$ 值がないということが起こる。 また、逆に $\widehat{\phi}$ のち Remesh 後に $\widehat{\phi}_{R} に$ 值が残らず消えて しまう部分が生じることになる。これを図解すると図

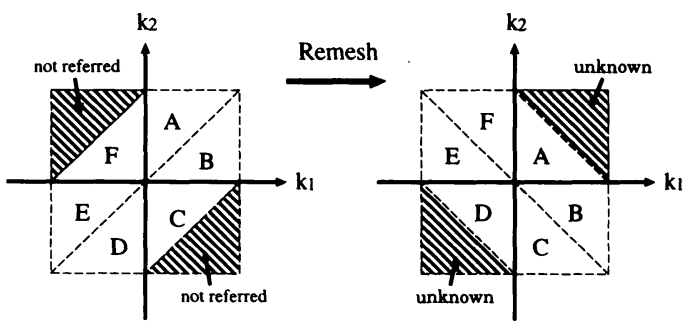

Fig. 4 Aliasing error

4 のようになる。図4の $A$ から $F$ の部分は対応関係があ るが, およそ全体の 4 分の 1 にあたる斜線部でデータが 失われることになる。斜線部が高波数部に限られてい ることから、主に散逸率などの微分量の評価に著しい 影掣が出ることが予想され，㻌送方程式の評価などに は向かないと思われる。ここで, データが失われないた めには $A$ から Fの範囲で限定して計算できるよう(斜線

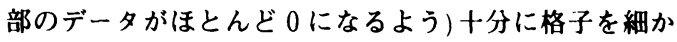
くする必要があるが,このことは計算量を二乗のオータ で増やすことになり不経済である。言いかえれば、限ら れた時間で計算できる乱流のレイノルズ数が相対的に 小さくなることを意味する。

\section{$3 \cdot 2$ 差分法による計算方法 前節で示した通} り,スペクトル法のみを用いた計算には䦓題が多い。こ のため本研究では $x_{2}$ 方向だけに差分法を用い,その他 の方向にはスペクトル法を用いることにより,スペクト ル法の精度を保ちながら remeshをしない計算法を探用 した。まず,式(17)〜 (20)を次のように分解する。第 1 段目の積分は

$$
\begin{aligned}
\rho_{, t}= & -\left(\rho u_{j}^{\prime}\right)_{, j}, \\
\left(\rho u_{i}^{\prime}\right)_{, t}= & -\left(\rho u_{j}^{\prime} u_{i}^{\prime}\right)_{, j}-\rho S u_{, .2}^{\prime} \delta_{i 1}-p_{, i} \\
& +\frac{1}{\operatorname{Re}}\left\{u_{i, a a}^{\prime}+\frac{1}{3}\left(u_{a, a}^{\prime}\right)_{, i}\right\}, \\
p_{. t}= & -u_{a}^{\prime} p_{., a}-\gamma p u_{a, a}^{\prime}+\frac{\gamma(p / \rho)_{, a a}}{\operatorname{Re} P_{r}}+\frac{(\gamma-1) \Phi}{\operatorname{Re}}(31)
\end{aligned}
$$

を行なう。第 2 段目は残りの部分の積分を行なう。

$$
\begin{aligned}
\frac{\partial \rho}{\partial t} & =-S x_{2} \frac{\partial \rho}{\partial x_{1}}, \\
\frac{\partial\left(\rho u_{i}^{\prime}\right)}{\partial t} & =-S x_{2} \frac{\partial\left(\rho u_{i}^{\prime}\right)}{\partial x_{1}}, \\
\frac{\partial p}{\partial t} & =-S x_{2} \frac{\partial p}{\partial x_{1}} .
\end{aligned}
$$

第 1 段目の積分に関しては何ら問題がないので説明は 省くとして、問題は第 2 段目である。3つの式はすべて

$$
\frac{\partial \phi}{\partial t}=-S x_{2} \frac{\partial \phi}{\partial x_{1}}
$$

という形をしているが、これは $\phi$ が $x_{1}$ 方向に速度 $S r_{2}$ で並行移動することを表しているのに過ぎない。この 式の時間積分によって $\phi_{i}$ が $\Delta t$ 時間後に $\phi_{i+1}$ になると 
すると,湤密に

$$
\phi_{i+1}\left(x_{1}\right)=\phi_{i}\left(x_{1}-\Delta t S x_{2}\right),
$$

と春けるが, $\phi_{i+1}$ は $\phi_{i}$ を $x_{1}$ 方向に $\Delta t S x_{2}$ だけ並行移動 したものであることがわかる。このことは次のように しても示せる。式(35)において, 空間微分には1次の風 上差分,時間樌分には 1 次の陽解法を用いると,

$$
\frac{\phi_{i+1}\left(x_{1}\right)-\phi_{i}\left(x_{1}\right)}{\Delta t}=-S x_{2} \cdot \frac{\phi_{i}\left(x_{1}\right)-\phi_{i}\left(x_{1}-S x_{2} \Delta t\right)}{\Delta x_{1}} \text {. }
$$

さらに,タイムステップをCFL 条件いっぱいの

$$
\frac{S x_{2} \Delta t}{\Delta x_{1}}=1
$$

となるように設定すると,式 $(36)$ の解を得る。1 次の風 上差分や 1 次の陽解法は誤差の大きそうな手法に見え るが, それらを用いても、線形の式でクーラン数を 1 に とった時のみ敞密解を与えることが知られている(14)。 さて,式 $(36)$ を実際にどのように通用するかだが, 先に 書いたように $x_{1}, x_{3}$ 方向にはスペクトル法を用いるの で,

$$
\phi_{i}\left(x_{1}, x_{2}, x_{3}\right)=\sum_{\boldsymbol{k}} \widehat{\phi}_{i}\left(k_{1}, x_{2}, k_{3}\right) \exp \left[2 \pi i\left(\frac{k_{1} x_{1}}{L_{1}}+\frac{k_{3} x_{3}}{L_{3}}\right)\right],
$$

と書ける ( $L$ は計算領域の長さ)。これを式 $(36)$ に代入 すると,

$$
\widehat{\phi}_{i+1}\left(k_{1}, x_{2}, k_{3}\right)=\hat{\phi}_{i}\left(k_{1}, x_{2}, k_{3}\right) \exp \left(-2 \pi i k_{1} \frac{L_{2}}{L_{1}} \Delta t S \frac{x_{2}}{L_{2}}\right),
$$

を得る。波数空間では式(35)の積分はこの操作に相当 する。

3. 3 境界条件境界条件について説明する。 $x_{1}, x_{3}$ 方向は周期境界条件で問題ないか， $x_{2}$ 方向の境界 条件はスペクトル法のみを用いる場合と違って周期境 界にならない。これは今用いる座標が乱流構造と共に 移娌する Lagrange座標でなくて，座標は静止してその 上を乱流構造の方が移動する Euler 座標であるからであ る。Euler座標における乱流構造の移動の様子を図5に 示す。斜線で粱った乱流構造は最初左図のようになっ
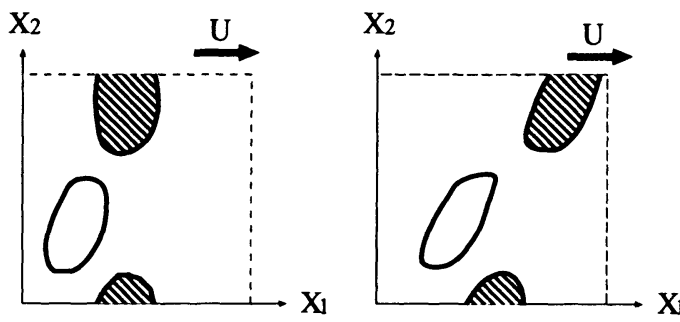

Fig. 5 Euler coordinate system

ていて, $x_{2}$ 方向に周期境界条件を用いることができる。
しかし，時間がたつと上の方が速く流されて右図のよう になるため $x_{2}$ 方向に周期境界を課すことができない。 境界条件は， $x_{2}$ の位置ごとに移動する距離が異なるこ とを考虑して次のように与える。

$$
\begin{aligned}
& \phi\left(x_{1}, x_{2}+L_{2}, x_{3}\right)=\phi\left(x_{1}-L_{2} S t, x_{2}, x_{3}\right), \\
& \phi\left(x_{1}, x_{2}-L_{2}, x_{3}\right)=\phi\left(x_{1}+L_{2} S t, x_{2}, x_{3}\right) .
\end{aligned}
$$

式だけみるとよく分からないので,図6をもちいて解説 する。まず,左側の図をみる。斜線部分が計算領域であ
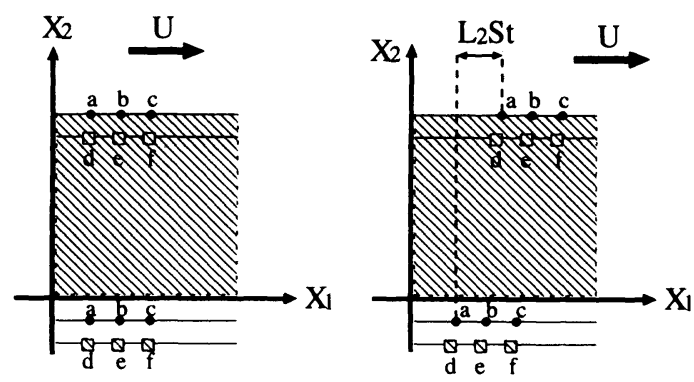

Fig. 6 Boundary conditions on the Euler coordinate system

るが, $x_{2}=0$ 付近で微分值を求めるには $x_{2}=0$ よりも下 の計算領域の外側の点 $(a \sim f)$ のデータが必要になる。 ここで $t=0$ の時には周期境界条件が成り立つので,左 側の図のようにa〜 $f$ 点のデータはそれぞれの真上の 点a〜 $f$ から持ってこれる。ところが, 計算が進行して くると, 右側の図のように計算領域より下側の $a \sim f の$ 点に対応する計算領域内の $a \sim f$ の点の位置が自分の

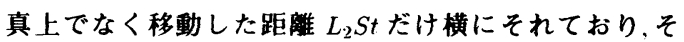
この点を参照しなければならない。このようなことは, 位置 $x_{2}$ によって平均流のスピードが異なるために発生 する。 $L_{2} S t$ は時間変化するので境界条件は毎ステップ ごと変化し, $L_{2} S t=L_{1}$ になった時 $t=0$ の時と同じ周期 境界条件に戻る。境界条件をスペクトル空間で表示す ると,

$$
\begin{aligned}
& \hat{\phi}\left(k_{1}, x_{2}+L_{2}, k_{3}\right)=\hat{\phi}\left(k_{1}, x_{2}, k_{3}\right) \exp \left(-2 \pi i k_{1} \frac{L_{2}}{L_{1}} S t\right)(43) \\
& \hat{\phi}\left(k_{1}, x_{2}-L_{2}, k_{3}\right)=\hat{\phi}\left(k_{1}, x_{2}, k_{3}\right) \exp \left(2 \pi i k_{1} \frac{L_{2}}{L_{1}} S t\right),(44)
\end{aligned}
$$

と書ける。

$3 \cdot 4$ 空間微分 空間微分については, $x_{1}, x_{3}$ 方向 にはスペクトル法を, $x_{2}$ 方向には 6 次の Páde scheme ${ }^{(13)}$ を用いた。Páde schemcは陰的差分法の一種であり,そ の 6 次の式は次のように与えられる。まず $u_{i}$ の一階微 分 (first derivative) $u_{i}^{\prime}$ に関しては,

$$
u_{i+1}^{\prime}+3 u_{i}^{\prime}+u_{i-1}^{\prime}=\frac{14}{3} \cdot \frac{u_{i+1}-u_{i-1}}{2 \Delta x}+\frac{1}{3} \cdot \frac{u_{i+2}-u_{i-2}}{4 \Delta x},
$$


二階微分 (second derivative) $u_{i}^{\prime \prime}$ に関しては,

$$
u_{i+1}^{\prime \prime}+\frac{11}{2} u_{i}^{\prime \prime}+u_{i-1}^{\prime \prime}=6 \cdot \frac{u_{i+1}-u_{i-1}}{\Delta x^{2}}+\frac{3}{2} \cdot \frac{u_{i+2}-u_{i-2}}{4 \Delta x^{2}},
$$

と与えられる。6 次の Páde schemeでは $u_{i}^{\prime} や u_{i}^{\prime \prime}$ か $u_{i}$ か ら直接求まらず, 3 重対角行列を解かなければ求まらな いことがわかる。また, 3 重対角行列を解くことから， 微分値を求める時にその左右の值だけでなく計算領域 すべての点のデータを参照するというスペクトル法に 似た特幑がある。ここで, 6 次の Páde schemeの精度に ついてスペクトル法および 2 次の中心差分と比較検討 する。例として,周期境界条件を満たすあるデータ $f(x)$ を仮定し次のようにおく。

$$
f(x)=\sum_{k=-N / 2}^{N / 2} \hat{f}(k) \exp (i k x), \quad(0 \leq x \leq 2 \pi) .
$$

これを

$$
x_{j}=\frac{2 \pi j}{N},
$$

と等間隔 $(\Delta x=2 \pi / N)$ に離散化すると

$$
f\left(x_{j}\right)=\sum_{k=-N / 2}^{N / 2} \hat{f}(k) \exp \left(\frac{2 \pi i j}{N}\right),
$$

となる。スペクトル法の場合は微分の誤差が 0 で

$$
\begin{aligned}
& \hat{f}^{\prime}(k)=i k \hat{f}(k), \\
& \hat{f}^{\prime \prime}(k)=-k^{2} \hat{f}(k),
\end{aligned}
$$

である。之次の中心差分では

$$
\begin{aligned}
f^{\prime}\left(x_{j}\right) & =\frac{f\left(x_{j+1}\right)-f\left(x_{j-1}\right)}{2 \Delta x}, \\
f^{\prime \prime}\left(x_{j}\right) & =\frac{f\left(x_{j+1}\right)-2 f\left(x_{j}\right)+f\left(x_{j-1}\right)}{\Delta x^{2}},
\end{aligned}
$$

であるから

$$
\begin{aligned}
\hat{f}^{\prime}(k) & =i \hat{f}(k) \cdot \frac{N}{2 \pi} \sin k^{\prime}, \\
\hat{f}^{\prime \prime}(k) & =\hat{f}(k) \cdot\left(\frac{N}{2 \pi}\right)^{2}\left(\cos k^{\prime}-1\right),
\end{aligned}
$$

となる。6 次の Páde schemeでは,

$$
\begin{aligned}
& \hat{f}^{\prime}(k)=i \hat{f}(k) \frac{N}{2 \pi} \frac{\frac{14}{3} \sin k^{\prime}+\frac{1}{6} \sin 2 k^{\prime}}{3+2 \cos k^{\prime}}, \\
& \hat{f}^{\prime \prime}(k)=\hat{f}(k)\left(\frac{N}{2 \pi}\right)^{2} \frac{12\left\{\cos k^{\prime}-1\right\}+\frac{3}{4}\left\{\cos 2 k^{\prime}-1\right\}}{\frac{11}{2}+2 \cos k^{\prime}}(57)
\end{aligned}
$$

となる $\left(k^{\prime} \equiv 2 \pi k / N\right.$ である)。各スキームでの一階微分 の此較を図7に示し, 二階微分の比較を図8に示す。ス ペクトル法の解に近いほど良いわけだが， 2 次の中心差 分では高波数域で著しく精度が悪い。一方, 6 次の Páde schemeでは高波数域での精度がかなり改善されている ことがわかる。また,打ち切り周波数の $2 / 3$ 程度までは 6 次の Páde scheme とスペクトル法がほほ同じ精度を 保つことから，微分に関して両者の精度を同じにするに は 6 次の Páde schemeの格子点の数をスペクトル法で 用いるモードの数の約 1.5 倍にすればよいと言总る。本

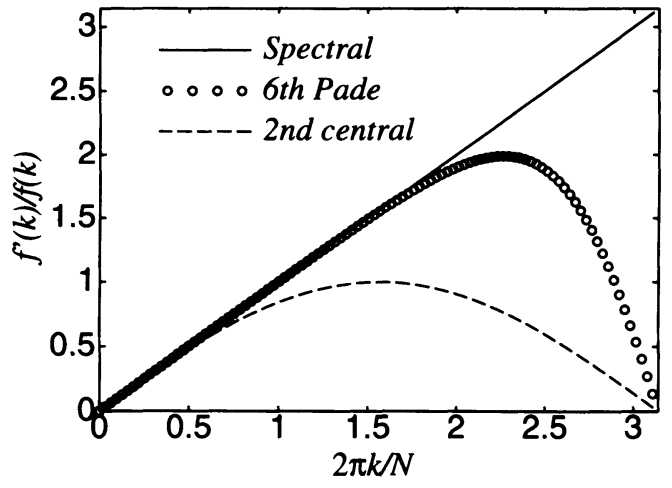

Fig. 7 First derivative approximations

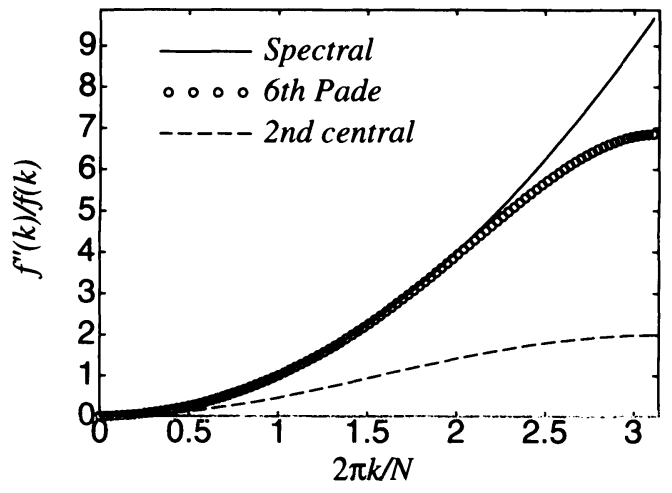

Fig. 8 Second derivative approximations

研究においては各方向での精度を均一に保つため、6 次の Páde schemeを用いる $x_{2}$ 方向の格子点数は $x_{1}, x_{3}$ に 適用したスペクトル法のモード数の 1.5 倍にした。

3 -5 時間樌分 時間積分には 3 次の Rungc-liutta 法を用いる(15)。

$$
\frac{\partial y}{\partial t}=f(y)
$$

という式をタイムステップ $\Delta t て ゙ y^{n} \rightarrow y^{n+1}$ に積分する には

$$
\begin{aligned}
y^{i} & =y^{n}+\frac{8}{15} f\left(y^{n}\right) \Delta t, \\
y^{i i} & =y^{n}+\frac{1}{4} f\left(y^{n}\right) \Delta t+\frac{5}{12} f\left(y^{i}\right) \Delta t, \\
y^{n+1} & =y^{n}+\frac{1}{4} f\left(y^{n}\right) \Delta t+\frac{3}{4} f\left(y^{i i}\right) \Delta t,
\end{aligned}
$$

とする。

3 -6 計算条件 計算格子を図9に示す。一様せ ん断乱流では乱流構造が流れ方向に伸びるので、, $x_{1}$ 方 向には $x_{2}, x_{3}$ 方向の倍の大きさの計算領域を取ってい る。格子点数は流れ方向 $x_{1}$ に 192 点, せん断方向 $x_{2}$ に 144 点，スパン方向 $x_{3}$ に 96 点とった。スペクトル法を 


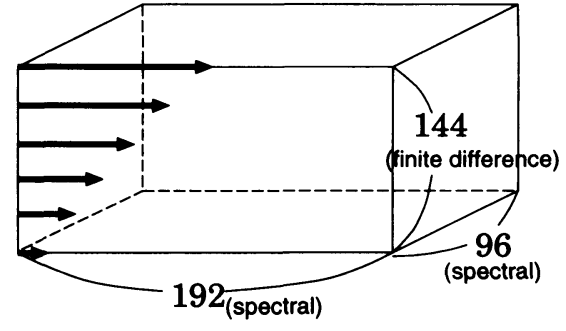

Fig. 9 Computation domain

用いて非線形項を計算する場合の aliasing error は $3 / 2$ rule で除去した。初期条件では, 圧力と密度の乱れは 0 ,初期の速度乱れは $\nabla \cdot \boldsymbol{u}^{\prime}=0$ を満たしている。ここ では, $M_{t}(\equiv \sqrt{2 k} / \bar{a})=0.27, \operatorname{Re}_{T}(\equiv \sqrt{4 k / \nu \epsilon})=220, S^{*}(\equiv$ $S \cdot k / \epsilon)=4.1$, という初期条件での計算の結果を示す。 乱れエネルギ $k$ 及び, レイノルズ応力の非等方テンソル $b_{i j}\left(\equiv \overline{u_{i}^{\prime} u_{j}^{\prime}} / k-\frac{2}{3} \delta_{i j}\right.$ ) の変化(図 10,11),St = 10 における流 れ方向速度変野 $u_{1}^{\prime}$ の等值線図(図 12) を示す。圧縮性の 乱流においても,流れ方向から 30 度程度傾いた細長い 構造が支配的であることが確認できる。

\section{4. 結言}

本研究では, スペクトル法の精度の良さを利用しつ つ,一部に高次精度养分を用いてRemesh を回避すると いう計算法を開発し,圧縮性の一様せん断乱流の計算を 行なった。

\section{文献}

(1) Zeman, O., 1990, Phys. Fluids A, Vol.2. No.2, 178 188.

(2) Yoshizawa, A., 1992, Physical Revicw A, vol.46, No.6, 32923306.

(3) Sarkar, S., 1992, Phys. Fluids A, Vol.4, No.12, 2674- 2682.

(4) Yoshizawa, A., 1995, Phys. Fluids, Vol.7, No.12, 31053117.

(5) Viegas, J.R. \& Rubesin, M.W., 1990, AIAA 91 1783.

(6) Sarkar, S. \& Lakshmanan, B., 1991, AIAA J., Vol.29, No.5, 743-749.

(7) Wilcox, D.C., 1992, AIAA J., Vol.30, No.11, 2639-2646.

(8) Sarkar, S., G.Erlebacher, M.Y.Hussaini \& H.O.Kreiss, 1991, J. Fluid Mech., vol.227, $473-493$.

(9) Blaisdell, G.A., N.N.Mansour \& W.C.Reynolds, 1991, NASA TF- 50.

(10) Rogers, M. \& Moin, P., 1987, J. Flıid. Mech., Vol.176, 3366.

(11) Rogallo, R.S., 1981, NASA TM 81315.

(12) Gerz, T., U.Schumann \& E.Elghobashi, 1989, J. Fluid Mech., Vol.200, 563594.

(13) Lele, S.K., 1992, J. Comp. Phys., Vol.103, 14 42.

(14) 相冒 秀明, 1995, 私信.

(15) Lce, S., Moin, P. \& S.K.Lele, 1992, NASA TF 52

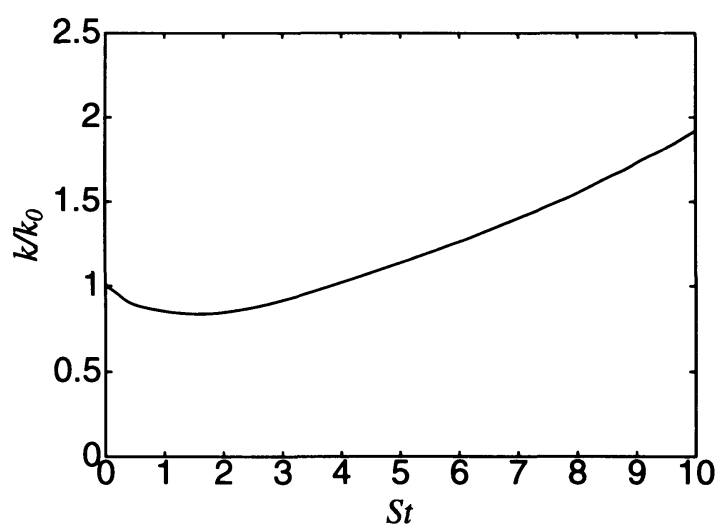

Fig. 10 Evolutions of turbulent energy $k / k_{0}$

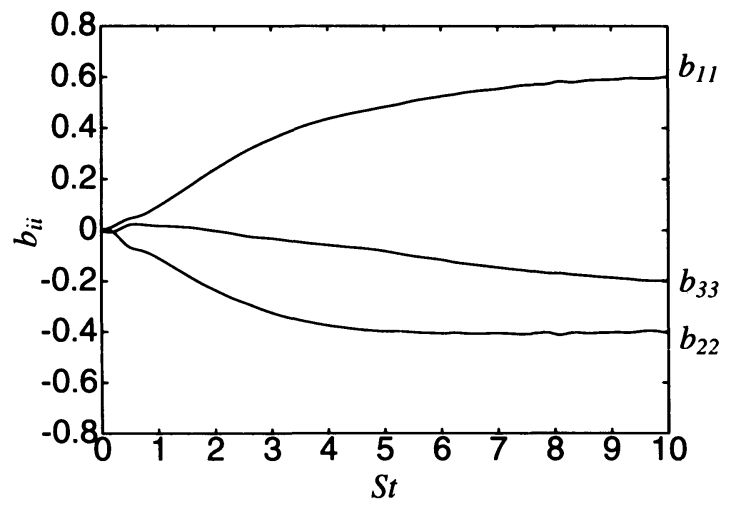

Fig. 11 Evolutions of the Reynolds stress anisotropy tensor

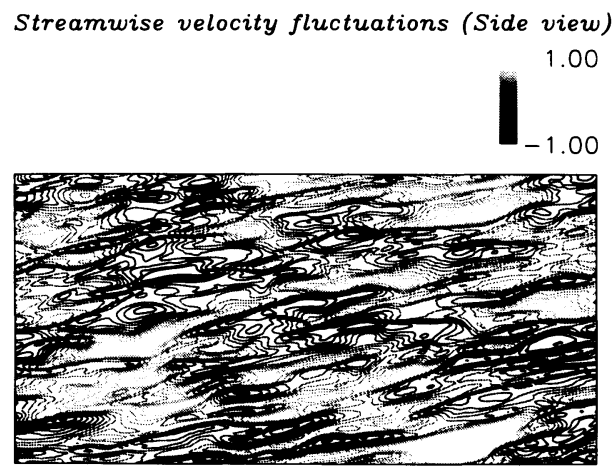

Fig. 12 Contours of the streamwize turbulent velocity on the $\left(x_{1}, x_{2}\right)$ plane at the time $\left.\mathrm{St}=10\right)$ 